\title{
Is there a science of recovery and does it matter?
}

\author{
INVITED COMMENTARY ON... RECOVERY AND THE MEDICAL MODEL ${ }^{\dagger}$ \\ Frank Holloway
}

Abstract In this issue of APT Mountain \& Shah seek to reconcile the currently fashionable 'recovery' paradigm of mental healthcare with the distinctly unfashionable 'medical model' of psychiatric practice. I argue that their article raises more questions than it answers - not least whether the recovery concept is amenable to empirical analysis.

Mountain \& Shah (2008, this issue) address an interesting issue - the relationship between what they term 'the recovery approach' and the 'medical model'. As scientist-practitioners they acknowledge a severe problem in their enterprise: the terms 'recovery' and 'medical model' are both poorly defined, so a systematic analysis of the relationship between the two presents formidable difficulties. They get over this problem by (a) using the particular concept of recovery adopted by Resnick et al (2004a), and (b) using their own definition of the medical model, the somewhat enigmatic 'does it work?' (Shah \& Mountain, 2007). They then look at the four dimensions of recovery as defined by Resnick et al $(2004 a, b)$ - life satisfaction, hope and optimism, empowerment, and information - through the prism of 'does it work?' They conclude, to their own satisfaction, that 'it' does indeed work - so there is no incompatibility between recovery and the medical model. Although in a formal sense their enterprise is successful the premises they adopt do deserve critical scrutiny.

\section{Recovery}

Regular readers of APT should be familiar with some of the complexities surrounding the concept of recovery as it is employed in contemporary discourse (Oyebode, 2004; Roberts \& Wolfson, 2004) and

See pp. 241-244, this issue. would be unlikely to dissent from the proposition that 'recovery should be the guiding purpose for future mental health services' (Roberts \& Hollins, 2007). As Mountain \& Shah note, two broad, though not necessarily incompatible, approaches to recovery from mental illness are usually identified (Resnick et al, 2004a). These might loosely be characterised as (1) the ordinary-language 'recovery-as-gettingbetter' and (2) the contemporary conceptualisation of 'recovery as a journey of the heart', a deeply individual process that is linked with finding personal meaning even in the face of ongoing illness and disability (Deegan, 1996). This second conceptualisation is linked with a further strand within the recovery movement, which focuses on the rights of people living with mental illness to social inclusion and self-determination and springs from the broader disability rights movement (Davidson et al, 2006).

What Mountain \& Shah do not acknowledge in their editorial is that the four elements of the recovery concept identified by Resnick et al $(2004 a, b)$ are by no means universally agreed as uniquely significant within the burgeoning recovery movement, although the centrality of hope is undoubtedly a common theme and the empowerment of service users a frequent subtext to the literature (Roberts \& Hollins, 2007). The data used by Resnick et al $(2004 a, b)$ belong to a very 'medical model' (or perhaps better a 'biopsychosocial model' ) study carried out in the early 1990s by health service researchers located firmly in the mental health mainstream. Although their primary research may have been influenced by the

Frank Holloway is a consultant psychiatrist and Clinical Director of the Croydon Integrated Adult Mental Health Service (Bethlem Royal Hospital, Monks Orchard Road, Beckenham, Kent BR3 3BX, UK. Email: f.holloway@iop.kcl.ac.uk). He is Chair of the Faculty of Rehabilitation and Social Psychiatry at the Royal College of Psychiatrists. His clinical and research interests include rehabilitation, mental health services and mental health law. 
recovery zeitgeist, which was already prominent in the USA at that time, it was not specifically designed to explore the recovery concept.

\section{The medical model}

The 'medical model' tends to be used as a term of abuse by non-psychiatrists. It appears, only to be dismissed, in the marginalia of a standard text on the philosophical underpinnings of our understanding of mental disorder (Bolton \& Hill, 1996). Tyrer \& Steinberg (1998: p. 5) described the medical model as 'a rhetorical device that obscures more than it clarifies'. They went on to identify and then synthesise five conceptual models of mental disorder: the disease model, the psychodynamic model, the behavioural model (which relates to operant-conditioning paradigms), the cognitive model, and the social model.

There is an undoubted tension between 'biological' and 'psychological' formulations of mental illness that goes back a very long way and can be seen to have ebbed and flowed over time. Thirty years ago, Engel (1977), a psychiatrist, advocated very persuasively for a bio-psychosocial model of healthcare that 'provides a blueprint for research, a framework for teaching, and a design for action in the real world of health care'. Subsequently a vast amount of evidence has accumulated that mental disorder occurs in the context of a complex interaction between biological, psychological and social factors, including very important gene-environment interactions in which the causal flow is by no means all one way.

For Tyrer \& Steinberg (1998) a conceptual model is helpful only if it provides an agenda for action that can be of demonstrable value as to 'what works' in the situations that patients and practitioners experience. In an earlier publication, Shah \& Mountain (2007) adopt this perspective but, perhaps unhelpfully, arrogate it solely to the 'medical model', presumably on the grounds that doctors are, uniquely among mental healthcare professionals, oriented towards action that is pragmatic and evidence based. This is a somewhat bold claim that may not necessarily endear psychiatrists to their professional and lay colleagues in the joint enterprise of tackling the consequences of mental illness and mental disorder.

\section{The way forward?}

'Does it work?' is both a rather good question and one that begs two obvious further questions: how do we formulate the 'it' (in this case the term recovery) and what do we mean by 'work'? Key figures in the recovery movement in the USA are quite convinced (and convincing) that the concepts underlying the movement are amenable to the sorts of empirical analysis familiar to mental health services researchers (Resnick et al, 2004a,b; Davidson et al, 2006). However, the task is likely to be formidably complex, with different concepts requiring different analytical strategies: whether treatment approach $x$ improves recovery-asoutcome compared with standard treatments is clearly amenable to the traditional randomised controlled trial, perhaps supplemented by healtheconomic analysis; identifying ways that people find meaning while living with serious mental illness demands a narrative approach; assessing the impact of recovery-oriented training on staff attitudes and practices can be addressed using standard social science methodologies; looking at the outcome of social policies and legislation aimed at promoting the rights of people living with mental illness requires yet other methodologies drawn from social research. Incidentally, in investigating recovery, pace Shah \& Mountain (2007), we are clearly straying wildly from traditional 'medical model' territory.

Any form of empirical analysis requires a degree of standardisation and indeed simplification that many proponents of recovery will find a distasteful irrelevance given the self-evident truth of the key humanistic values underlying the recovery movement. These values are implied by words such as 'empowerment', 'wellness', 'health', 'strengths', 'hope', 'meaning', 'social inclusion' and 'personal identity' that commonly occur in the recovery narrative (see, for example, Care Services Improvement Partnership, 2007: section 3.3): surely no reasonable person of good will would advocate as a policy 'disempowerment', 'illness', 'weakness', 'despair', 'exclusion' and 'dehumanisation' for any social group.

My personal view is that there is a science to be discovered behind the warm words adopted (or perhaps captured) by the advocates of recovery. Identifying how best to promote the self-evident goods of 'empowerment', 'wellness', 'hope' and 'meaning' for people living with mental illness will not be easy. There are potentially knotty problems here, for example, about how we should weigh in healtheconomic terms one person's ordinary-language recovery from an episode of bipolar disorder against another's experience of empowerment despite continuing disability (a word notably absent from the UK recovery discourse). It will require cooperation between the high priests of the recovery movement and interested and necessarily highly sophisticated mental healthcare and social policy researchers. In this issue of $A P T$, Mountain \& Shah have done us a service by placing these issues firmly on the UK mental health agenda. 


\section{Declaration of interest}

None.

\section{References}

Bolton, D. \& Hill, J. (1996) Mind, Meaning and Mental Disorder. The Nature of Causal Explanation in Psychology and Psychiatry. Oxford University Press.

Care Services Improvement Partnership (2007) A Common Purpose: Recovery in Future Mental Health Services. CSIP.

Davidson, L., O'Connell, M., Tondora, J., et al (2006) The top ten concerns about recovery encountered in mental health system transformation. Psychiatric Services, 57, 640-645.

Deegan, P. (1996) Recovery as a journey of the heart. Psychiatric Rehabilitation Journal, 19, 91-97.

Engel, G. L. (1977) The need for a new medical model: a challenge for biomedicine. Science, 196, 192-196.
Mountain, D. \& Shah, P. (2008) Recovery and the medical model. Advances in Psychiatric Treatment, 14, 241-244.

Oyebode, F. (2004) Invited commentary on: The rediscovery of recovery. Advances in Psychiatric Treatment, 10, 48-49.

Resnick, S. G., Rosenheck, R. A. \& Lehman, A. F. (2004a) An exploratory analysis of correlates of recovery. Psychiatric Services, 55, 540-547.

Resnick, S. G., Fontana, A., Lehman, A. F., et al (2004b) An empirical conceptualization of the recovery orientation. Schizophrenia Research, 75, 119-128.

Roberts, G. \& Hollins, S. (2007) Recovery: our common purpose. Advances in Psychiatric Treatment, 13, 397-399.

Roberts, G. \& Wolfson, P. (2004) The rediscovery of recovery: open to all. Advances in Psychiatric Treatment, 10,37-48.

Shah, P. \& Mountain, D. (2007) The medical model is dead long live the medical model. British Journal of Psychiatry, 191, 375-377.

Tyrer, P. \& Steinberg, D. (1998) Models for Mental Disorder. Conceptual Models in Psychiatry. John Wiley \& Sons. 